Sharif University of Technology
Scientia Iranica
SCIENTIA
I RAN I CA
http://scientiairanica.sharif.edu

\title{
Standard equations for predicting the discharge coefficient of a modified high-performance side weir
}

\author{
A.H. Zaji $i^{a, *}$, H. Bonakdari ${ }^{a}$, and Sh. Shamshirband ${ }^{b}$ \\ a. Department of Civil Engineering, Razi University, Kermanshah, Iran. \\ b. Department of Computer System, Faculty of Computer Science and Information Technology, University of Malaya, 50603 Kuala \\ Lumpur, Malaysia.
}

Received 4 March 2016; received in revised form 15 December 2016; accepted 31 July 2017

\section{KEYWORDS}

Discharge coefficient;

Modified triangular

side weir;

Nonlinear regression;

Particle swarm

optimization;

Standard equation.

\begin{abstract}
Side weirs are hydraulic structures that are used as discharge adjustments to divert the surplus water flowing from the main channel. Predicting the discharge coefficient is one of the most important parameters in the side weir design process. In practical situations, it is preferred to predict the discharge coefficient with simple equations. The goal of this study is to develop accurate standard equations for use in predicting the discharge coefficient of a high-performance, modified triangular side weir. The Particle Swarm Optimization (PSO) algorithm was used to optimize the parameters of the equations. Four different forms of the equations and two non-dimensional input combinations were used to develop the most appropriate model. The results obtained by our simple standard equations optimized by the PSO algorithm were compared with those of complex nonlinear regression equations, and our equations were more accurate in modeling the discharge coefficient. Our method reduced the error in the results by as much as $43 \%$ compared to the regression methods, and its simplicity makes it useful in solving practical problems.
\end{abstract}

(C) 2018 Sharif University of Technology. All rights reserved.

\section{Introduction}

In some rivers, water and wastewater, irrigation, and drainage channel zones, the flow rate may exceed the tolerance capacity of a river or channel. In such a case, discharge control structures, such as side weirs, can be used to control the flow and prevent overflows. Side weirs are also used to keep floods away from dam reservoirs and the diversion of flow for the sake of protection. The study of side weirs dates back to the early 20th century when De Marchi [1] laid the groundwork for other studies with his mathematical

\footnotetext{
*. Corresponding author.

E-mail addresses: amirzaji@gmail.com (A.H. Zaji);

bonakdari@yahoo.com (H. Bonakdari);

shahab1396@gmail.com (Sh. Shamshirband)
}

doi: $10.24200 /$ sci. 2017.4198 model of side weirs. The equations he developed to describe side weirs were based on the assumption that the specific energy was the same before and after the weirs.

In this paper, a model with a decreasing discharge equation is presented for a rectangular channel with a horizontal bed and a spatially-varied flow. The equation is:

$$
\frac{d y}{d x}=\frac{\frac{Q}{g b^{2} y^{3}}\left(\frac{-d Q}{d x}\right)}{1-\frac{Q^{2}}{g b^{2} y^{2}}}=\frac{Q y\left(\frac{-d Q}{d x}\right)}{g b^{2} y^{3}-Q^{2}}
$$

where $d y / d x$ is the depth change along the channel, $Q$ is the discharge of the flow, $y$ is the depth of the flow, $b$ is the width of the main channel, $d Q / d x$ is the discharge change along the channel, and $g$ is the acceleration of gravity. The discharge per unit length over the side weir equals: 


$$
-\frac{d Q}{d x}=\frac{2}{3} C_{M} \sqrt{2 g}(y-w)^{1 / 5}
$$

in which $C_{M}$ is the discharge coefficient, also known as the De Marchi coefficient. By assuming that the specific energy is constant, the discharge in the channel would be:

$$
Q=b y \sqrt{2 g(E-y)} .
$$

By inserting Eqs. (2) and (3) into Eq. (1), we obtain:

$$
\frac{d y}{d x}=\frac{4}{3} \frac{C_{M}}{b} \frac{\sqrt{(E-y)(y-w)}}{3 y-2 E} .
$$

Integrating the above equations and assuming $C_{M}$ independent of $x$ direction, we will have Eq. (5):

$$
x=\frac{3 b}{2 C_{M}} \phi(y, E, w)+c,
$$

where $\phi$ is obtained from Eq. (6). Therefore, $C_{M}$ obtained in the laboratory is calculated by substituting $\phi$ through Eq. (5) as follows:

$$
\phi(y, E, w)=\frac{2 E-3 w}{E-w} \sqrt{\frac{E-y}{y-w}}-3 \sin ^{-1} \sqrt{\frac{E-y}{E-w}} .
$$

Moreover, the length of the side weir is obtained from Eq. (7):

$$
L=x_{2}-x_{1}=\frac{3}{2} \frac{b}{C_{M}}\left(\phi_{2}-\phi_{1}\right)
$$

in which $\phi_{1}$ and $\phi_{2}$ are obtained from Eq. (6) for upstream and downstream of the weirs, respectively. Assuming that $Q_{1}$ and $Q_{2}$ are the upstream and downstream discharges, the amount of side weir discharge is obtained from Eq. (3).

Following De Marchi [1], many researchers have tried to calculate the side weir coefficients $\left(C_{M}\right)$, and most of them have considered $C_{M}$ as a function of the upstream Froude number $\left(\mathrm{Fr}_{1}\right)$ [2-6].

A significant number of researches have been conducted to increase the efficiency of the side weir by changing its geometrical situation, i.e. changing its rectangular crest to triangular, circular, or elliptical, causing an increase in both the length of the weir and the discharge coefficient. Borghei and Parvaneh [7] designed a modified triangular side weir whose discharge coefficient that was 2.33 times higher than a conventional side weir's in a rectangular channel. The authors used 200 test measurements and, finally, using the nonlinear regression method, determined an equation for the modified triangular side weir discharge coefficient, i.e. Eq. (8):

$$
\begin{aligned}
C_{M}= & \left.-0.18\left(\frac{\mathrm{Fr}_{1}}{\sin \theta^{\prime}}\right)^{0.71}-0.15\left(\mathrm{Fr}_{1}\right)^{0.44}+\left(\frac{w}{Y_{1}}\right)^{0.7}\right] \\
& \times\left[-2.37+2.58\left(\frac{w \sin \theta^{\prime}}{Y_{1}}\right)^{-0.36}\right]
\end{aligned}
$$

Soft computing methods are used as a new tool for calculating the side weir coefficient, and many researchers have considered their application in predicting scour depth [8-13], determining flow characteristics in different open channels [14,15], modeling rainfall and predicting stream flow [16-22], modeling coastal algal blooms [23], evapotranspiration [24,25], combined open channel flow [26,27], sediment transport [28,29], predicting ground water levels [30], and forecasting the demand for water [31-33]. In estimating the side weir coefficient, Bilhan et al. [34] studied different Artificial Neural Network (ANN) methods, and found that they have much higher accuracy than multiple nonlinear and linear regression models do. Using Radial Basis Neural Network (RBNN), Regression Neural Network (RNN), and Genetic Expression Programming (GEP), Kisi et al. [35] predicted the triangular side weir discharge coefficient. The results were compared with 2500 laboratory measurements, and it was found that ANN and GEP gave better results than regression methods. To determine side weir discharge coefficients, Emin Emiroglu et al. [36] used an adaptive neuro-fuzzy technique (ANFIS), the results of which indicated the high accuracy of the ANFIS method for modeling the side weir discharge coefficient. Some other studies have been published on modeling the triangular labyrinth side weir discharge using soft computing, all of which were proved better than the regression methods [37-42].

The objective of this study is to provide a practical, simple equation for calculating the discharge coefficient for a modified, high-performance triangular side weir. The Particle Swarm Optimization (PSO) algorithm was used to optimize each of the equations considered. Four different equation forms were developed using the input parameters of $\mathrm{Fr}_{1}$ (upstream Froude number), $w / L$ (weir height/weir length), $\operatorname{Fr}_{1} / \operatorname{sine}\left(\theta^{\prime}\right)$ (upstream Froude number/sine (weir included angle/2)), $w / Y_{1}$ (weir height/upstream flow depth), and $w \times \operatorname{sine}\left(\theta^{\prime}\right) / Y_{1}$ (weir height $\times$ sine (weir included angle/2)/upstream flow depth). Considering dimension $L$ (length) for $w, L$, and $Y_{1}$, it is obvious that all of the used input parameters are nondimensional. Finally, the accuracy of each equation was examined and compared.

\section{Experimental setup}

In this study, the laboratory model of Borghei and Parvaneh [7] was used, including a rectangular flume that was $11 \mathrm{~m}$ long and $0.4 \mathrm{~m}$ wide. The glass walls of the channel were $0.66 \mathrm{~m}$ high. The outlet discharges from the main and tributary channels $\left(Q_{2}\right.$ and $\left.Q_{w}\right)$ were measured by standard $V$ notches. The accuracies of the water head and discharge measurements were $\pm 1 \mathrm{~mm}$ and $\pm 0.0001 \mathrm{~m}^{3} / \mathrm{s}$, respectively. The authors performed 200 tests for different geometrical 
Table 1. Interval variations in experimental tests of Borghei and Parvaneh [7].

\begin{tabular}{|c|c|c|c|c|c|c|}
\hline$\theta\left({ }^{\circ}\right)$ & $L(\mathbf{m})$ & $w(\mathbf{m m})$ & $w / Y_{1}$ & $Q_{1}\left(\mathrm{~m}^{3} / \mathrm{s}\right)$ & $\mathrm{Fr}_{1}$ & Number of runs \\
\hline \multirow{2}{*}{30} & 0.3 & $50,75,100,150$ & \multirow{2}{*}{$0.46-0.83$} & \multirow{2}{*}{$0.019-0.030$} & \multirow{2}{*}{$0.19-0.96$} & \multirow{2}{*}{40} \\
\hline & 0.4 & $50,75,100,150$ & & & & \\
\hline \multirow{3}{*}{45} & 0.3 & $50,75,100,150$ & \multirow{3}{*}{$0.46-0.83$} & \multirow{3}{*}{$0.019-0.030$} & \multirow{3}{*}{$0.19-0.96$} & \multirow{3}{*}{55} \\
\hline & 0.4 & $50,75,100,150$ & & & & \\
\hline & 0.6 & $50,100,150$ & & & & \\
\hline \multirow{3}{*}{60} & 0.3 & $50,75,100,150$ & \multirow{3}{*}{$0.46-0.83$} & \multirow{3}{*}{ 0.019-0.030 } & \multirow{3}{*}{$0.19-0.96$} & \multirow{3}{*}{50} \\
\hline & 0.4 & $50,100,150$ & & & & \\
\hline & 0.6 & $50,100,150$ & & & & \\
\hline \multirow{3}{*}{70} & 0.3 & $50,75,100,150$ & \multirow{3}{*}{$0.46-0.83$} & \multirow{3}{*}{ 0.019-0.030 } & \multirow{3}{*}{$0.19-0.96$} & \multirow{3}{*}{55} \\
\hline & 0.4 & $50,75,100,150$ & & & & \\
\hline & 0.6 & $50,100,150$ & & & & \\
\hline
\end{tabular}
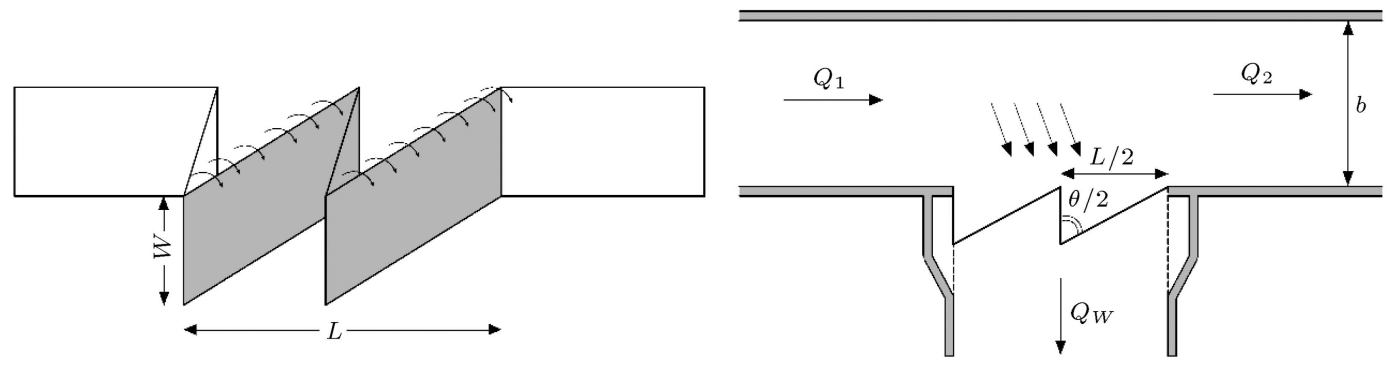

Figure 1. Plan view of modified triangular side weir and the parameters used.

conditions, opening lengths $(L)$, weir heights $(w)$, weir oblique angles $\left(\theta^{\prime}\right)$, and input discharges $\left(Q_{1}\right)$. All of the tests were conducted under certain conditions in which the upstream Froude number $\left(\mathrm{Fr}_{1}\right)$ was at the interval of $0.19-0.96$. Table 1 provides the parameters whose variation intervals are observed in the laboratory tests. Figure 1 shows the schema of the modified triangular side weir and the parameters used.

\section{Methods and materials}

In this study, the Particle Swarm Optimization (PSO) method was used to determine an accurate equation to predict the discharge coefficient. The design of this method was inspired by flocks of birds or schools of fish, because when they stay together, the likelihood of being caught reduces. This is called swarm intelligence. When fish make up a school, they follow only a few simple, yet systematic, rules; however, their behavior appears very complicated. In addition to the PSO algorithm, Ant Colony Optimization (ACO), Bees Algorithm (BA), and Artificial Fish Swarm (AFS) are all considered swarm intelligence methods.

\subsection{Particle Swarm Optimization (PSO)}

Kennedy and Eberhart [43] introduced the PSO. Initially, the authors intended to create a sort of social-based computational intelligence, independent of individual capabilities, i.e. individuals with normal intelligence quotients could make up a very intelligent community. Therefore, their study resulted in a reliable algorithm for optimization called Particle Swarm Optimization (PSO), in which there are some particles in space, and each particle has a potential solution to the problem. Each particle follows a general and fixed rule to move, called self-organization. Based on this rule, each particle remembers the present and past situations as well as the best-experienced situation through both the single particle and all of the particles. The new position of the particle is calculated from Eq. (9) as follows:

$$
\begin{aligned}
v^{i}[t+1]= & w v^{i}[t]+c_{1} r_{1}\left(x^{p \text { best }}[t]-x^{i}[t]\right) \\
& +c_{2} r_{2}\left(x^{g \text { best }}[t]-x^{i}[t]\right)
\end{aligned}
$$

In this equation, the first term on the right side of the equation represents a particle's movement toward its 
last movement; the second term indicates the velocity of a particle moving toward the best-known former position, and the third term shows the velocity of a particle moving toward the best previous position experienced by all particles. Herein, $x^{\text {pbest }}$ is the best personal memory, and $x^{g \text { best }}$ is the best collective memory. The inertia coefficient $(w)$ is an arbitrary factor that has values less than $1 ; r_{1}$ and $r_{2}$ are random numbers with a uniform distribution, while $c_{1}$ and $c_{2}$ are the individual and collective learning coefficients, respectively, ranging between 0-2 [43]. The three terms are the resultant vector of the amount and direction of and movement towards a new position. Thus, from Eq. (10), we will get a new position of the particle as follows:

$$
x^{i}[t+1]=x^{i}[t]+v^{i}[t+1] .
$$

Figure 2 demonstrates the steps of the PSO algorithm. Initially, the primary population is formed; then, the fitness function of each particle is determined. Subsequently, $p^{\text {best }}$ and $g^{\text {best }}$ are determined and, then, memorized in the particle's memory. Eq. (9) is used to determine the particle's velocity, namely the direction and amount of the movement of the particle; subsequently, the velocity is added to the

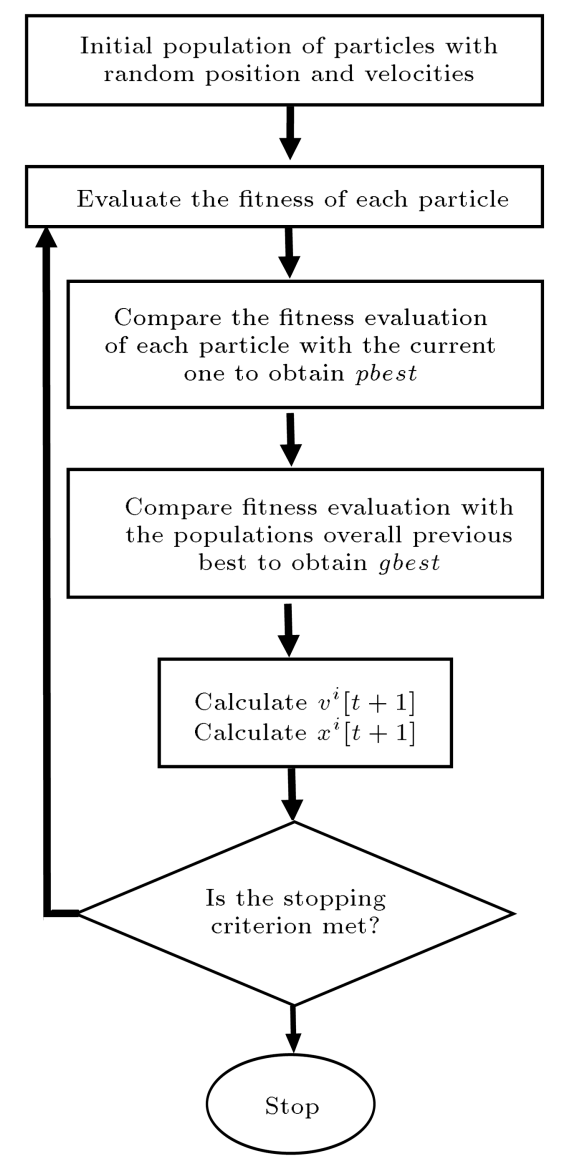

Figure 2. Particle swarm optimization flow chart. present particle's position to determine the particle's new position. Finally, the stopping criteria of the algorithm are checked. If the criteria have been met, the algorithm stops the process; otherwise, the loop is repeated. In all models here, the Number of Function Evaluation (NFE) is considered as a criterion for stopping the iterations at NFE $=100,000$.

If the inertia parameter $(w)$ reaches its maximum $(w=1)$, the algorithm's exploration property goes up; however, if $w$ is low, the algorithm's exploitation property increases. It is generally expected that the exploration property be high at the beginning, while it increase at the end; therefore, in the algorithm used here, the damping coefficient $\left(w_{\text {damp }}=0.98\right)$ was used $[44,45]$. At the end of each repetition, the inertia parameter $(w)$ decreases gradually, and as the results get closer to the end of the solution, $w$ decreases, leading to an increase in the exploitation of the model (Eq. (11)):

$$
w=w \times w_{\text {damp }} .
$$

\subsection{Objective function and model performance}

In this study which uses the PSO algorithm, some equations are given for modeling the discharge coefficient of a modified triangular side weir. The primary goal of PSO is to reduce the error that results from the proposed equation application, compared to the laboratory model. Therefore, according to Eq. (12), we have the following:

$$
e_{i}=f_{i}-\hat{f}_{i}
$$

where $f_{i}$ and $\hat{f}_{i}$ are the results of the laboratory model and the proposed equation, respectively. The algorithm uses Mean Square Error (MSE) to determine the iteration error, as shown in Eq. (13). In addition, in order to investigate the models' performance, Root Mean Squared Error (RMSE), Mean Average Error (MAE), and Mean Absolute Percentage Error (MAPE) are used (Eqs. (14)-(16)):

$$
\begin{aligned}
& \text { MSE }=\frac{1}{n} \sum_{i=1}^{n} e_{i}^{2}, \\
& \text { RMSE }=\sqrt{\frac{1}{n} \sum_{i=1}^{n} e_{i}^{2},} \\
& \text { MAE }=\frac{1}{n} \sum_{i=1}^{n}\left|e_{i}\right|, \\
& \text { MAPE }=\frac{\sum_{i=1}^{n}\left|e_{i}\right|}{\sum_{i=1}^{n} f_{i}} \times \frac{100}{n},
\end{aligned}
$$

where $n$ is the quantity of the input dataset. 


\section{Results}

To estimate $C_{M}$, four non-dimensional parameters $\left(\operatorname{Var}_{1}\right.$ to $\left.\operatorname{Var}_{4}\right)$ are considered as inputs in each of the following equations. These parameters are a combination of the upstream Froude number $\left(\operatorname{Fr}_{1}\right)$, side weir oblique angle $\left(\theta^{\prime}\right)$, weir height $(w)$, and upstream depth $\left(Y_{1}\right)$. As Eqs. (17) and (18) show, there are two possible input sets, i.e. INPUT1 and INPUT2, that can be considered for predicting the discharge coefficient $\left(C_{M}\right)$. The difference between the inputs is that INPUT2 considers the four parameters $\left(Y_{1}, w\right.$, $\left.\theta^{\prime}, \mathrm{Fr}_{1}\right)$ as well as the length effect of the side weir $(L)$ :

\section{INPUT1:}

$$
\begin{array}{r}
C_{M}=\varphi\left(\operatorname{Var}_{1}=\operatorname{Fr}_{1}, \operatorname{Var}_{2}=\frac{\operatorname{Fr}_{1}}{\sin \theta^{\prime}},\right. \\
\left.\operatorname{Var}_{3}=\frac{w}{Y_{1}}, \operatorname{Var}_{4}=\frac{w \sin \theta^{\prime}}{Y_{1}}\right),
\end{array}
$$

INPUT2:

$$
\begin{array}{r}
C_{M}=\varphi\left(\operatorname{Var}_{1}=\frac{w}{L}, \operatorname{Var}_{2}=\frac{\operatorname{Fr}_{1}}{\sin \theta^{\prime}},\right. \\
\left.\operatorname{Var}_{3}=\frac{w}{Y_{1}}, \operatorname{Var}_{4}=\frac{w \sin \theta^{\prime}}{Y_{1}}\right) .
\end{array}
$$

In order to study the effects of the considered input variables in Eqs. (17) and (18) on $C_{M}$, the sensitivity analysis of partial differential equations is used $[46,47]$. In this method, the ratio of the change in $C_{M}$ (as the output) to the change in the input variables considered in Eqs. (17) and (18) is examined. For the practical use of this method, the partial differential equation can be approximated as a finite difference [48] and output values calculated for the small changes in the input parameters [49]. The sensitivities of $\operatorname{Fr}_{1}, \frac{\operatorname{Fr}_{1}}{\sin \theta^{\prime}}, \frac{w}{Y_{1}}, \frac{w \sin \theta}{Y_{1}}$, and $\frac{w}{L}$ variables are $-0.66,-0.22,-0.89,-3.28$, and 1.27 , respectively. Thus, $\frac{w \sin \theta^{\prime}}{Y_{1}}$ and $\frac{w}{L}$ are the most important input parameters where $\frac{w \sin \theta^{\prime}}{Y_{1}}$ has a negative relation with $C_{M}$ and $\frac{w}{L}$ has a positive relation with $C_{M}$. In what follows, some standard equations are optimized to estimate the discharge coefficient $\left(C_{M}\right)$ by the PSO algorithm; then, the error of each equation is calculated.

\subsection{Optimized equation of Borghei and Parvaneh [7]}

Eq. (19) represents the structure of Eq. (8) used by Borghei and Parvaneh [7]. Table 2 shows the coefficients, i.e. $a_{1}$ to $a_{8}$, proposed in this study, estimated through nonlinear regression. In Eq. (19), INPUT1 is considered as the input variable. MSE of the equation, related to the laboratory results, is equal to 0.0037 (Table 2). Figure 3(a) compares the calculated and laboratory results. The $45^{\circ}$ line is the exact solution to the problem, and the closeness of the scatter to this line shows the accuracy of the model. Moreover, the fit line equation (assuming that the equation is $y=c_{1} x+c_{2}$ ) in Figure 3(a) shows the accuracy of the model and the deviation of the results from the exact line. Therefore, the closer $c_{1}$ is to one and $c_{2}$ is to zero, the greater the accuracy of the model will be. In Figure 3(b), the laboratory results are compared with those of Eq. (8)

Table 2. Characteristics and statistical errors of Eq. (8).

\begin{tabular}{ccccccccc}
\hline & $\boldsymbol{a}_{\mathbf{1}}$ & $\boldsymbol{a}_{\mathbf{2}}$ & $\boldsymbol{a}_{\mathbf{3}}$ & $\boldsymbol{a}_{\mathbf{4}}$ & $\boldsymbol{a}_{\mathbf{5}}$ & $\boldsymbol{a}_{\mathbf{6}}$ & $\boldsymbol{a}_{\mathbf{7}}$ & $\boldsymbol{a}_{\mathbf{8}}$ \\
\cline { 2 - 9 } INPUT1 & -0.18 & 0.71 & -0.15 & 0.44 & 0.70 & -2.37 & 2.58 & -0.36 \\
\cline { 2 - 9 } Eq. (8) & $\mathbf{M S E}$ & $\mathbf{R M S E}$ & MAE & MAPE & & & & \\
\cline { 2 - 9 } & 0.0037 & 0.016 & 0.0482 & 0.035 & & & & \\
\hline
\end{tabular}

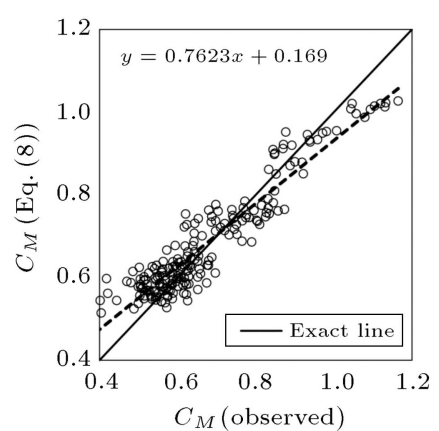

(a)

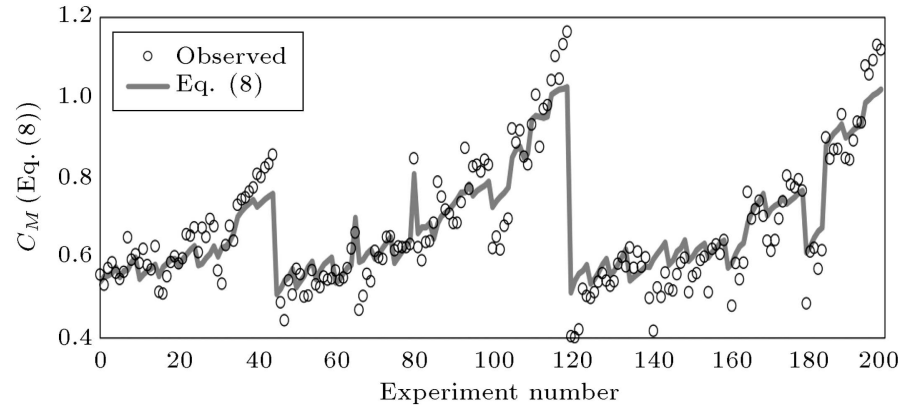

(b)

Figure 3. (a) Scatter plot of comparing the observed $C_{M}$ and the estimated $C_{M}$ by Eq. (8). (b) Comparison of the observed $C_{M}$ and the estimated $C_{M}$ by Eq. (8). 
to estimate $C_{M}$. The horizontal axis represents the number of datasets (200 tests), and the vertical axis shows the discharge coefficient $\left(C_{M}\right)$. Figure $3(\mathrm{a})$ shows that, in some parts, such as experiment numbers 20 to 40 and 100 to 120 , there is a greater error in Eq. (8) than in the laboratory results. However, for intervals with a minor sudden change in the discharge coefficient $C_{M}$, such as experiment numbers 120 to 160 , the results are closer together:

$$
\begin{aligned}
C_{M}= & {\left[a_{1}\left(\operatorname{Var}_{2}\right)^{a_{2}}+a_{3}\left(\operatorname{Var}_{1}\right)^{a_{4}}+\left(\operatorname{Var}_{3}\right)^{a_{5}}\right] } \\
& \times\left[a_{6}+a_{7}\left(\operatorname{Var}_{4}\right)^{a_{8}}\right] .
\end{aligned}
$$

To find an accurate and efficient equation for calculating $C_{M}$, coefficients $a_{1}$ to $a_{8}$ were calculated by the
PSO algorithm, instead of nonlinear regression. Table 3 shows Eq. (19.1) calculated based on INPUT1 as the input variable. The table shows that MSE is equal to 0.0024 , which is much lower than that of Eq. (8). In the next step, the input non-dimensional parameters were changed, and INPUT2 was used as an input variable for Eq. (19). Table 3 shows the related results obtained by Eq. (19.2). Since MSE decreased to 0.0021 while MSE of Eq. (19.1) was 0.0024, it is apparent that higher accuracy was attained using non-dimensional INPUT2. In Figure 4(a), the results from Eqs. (19.1) and (19.2) are given on the vertical axis; the laboratory test results are given on the horizontal axis. In both cases, the fit line is very close to the exact line. Eq. (19.2), calculated based on INPUT2, has much higher efficiency than Eq.

Table 3. Characteristics and statistical errors of Eqs. (19.1) and (19.2).

\begin{tabular}{ccccccccc}
\hline & $\boldsymbol{a}_{\mathbf{1}}$ & $\boldsymbol{a}_{\mathbf{2}}$ & $\boldsymbol{a}_{\mathbf{3}}$ & $\boldsymbol{a}_{\mathbf{4}}$ & $\boldsymbol{a}_{\mathbf{5}}$ & $\boldsymbol{a}_{\mathbf{6}}$ & $\boldsymbol{a}_{\mathbf{7}}$ & $\boldsymbol{a}_{\mathbf{8}}$ \\
\cline { 2 - 10 } INPUT1 & 0.34 & -0.37 & -0.18 & 3.07 & 2.34 & -0.53 & 0.87 & -0.63 \\
\cline { 2 - 10 } Eq. (19.1) & $\mathbf{M S E}$ & $\mathbf{R M S E}$ & $\mathbf{M A E}$ & $\mathbf{M A P E}$ & & & & \\
\cline { 2 - 10 } & 0.0024 & 0.049 & 0.0386 & 0.029 & & & & \\
\hline \multirow{3}{*}{ INPUT2 } & $\boldsymbol{a}_{\mathbf{1}}$ & $\boldsymbol{a}_{\mathbf{2}}$ & $\boldsymbol{a}_{\mathbf{3}}$ & $\boldsymbol{a}_{\mathbf{4}}$ & $\boldsymbol{a}_{\mathbf{5}}$ & $\boldsymbol{a}_{\mathbf{6}}$ & $\boldsymbol{a}_{\mathbf{7}}$ & $\boldsymbol{a}_{\mathbf{8}}$ \\
\cline { 2 - 10 } Eq. (19.2) & $\mathbf{M S E}$ & $\mathbf{R M S E}$ & $\mathbf{M A E}$ & $\mathbf{M A P E}$ & & & & \\
\cline { 2 - 10 } & 0.0021 & 0.046 & 0.0354 & 0.026 & & & & \\
\hline
\end{tabular}
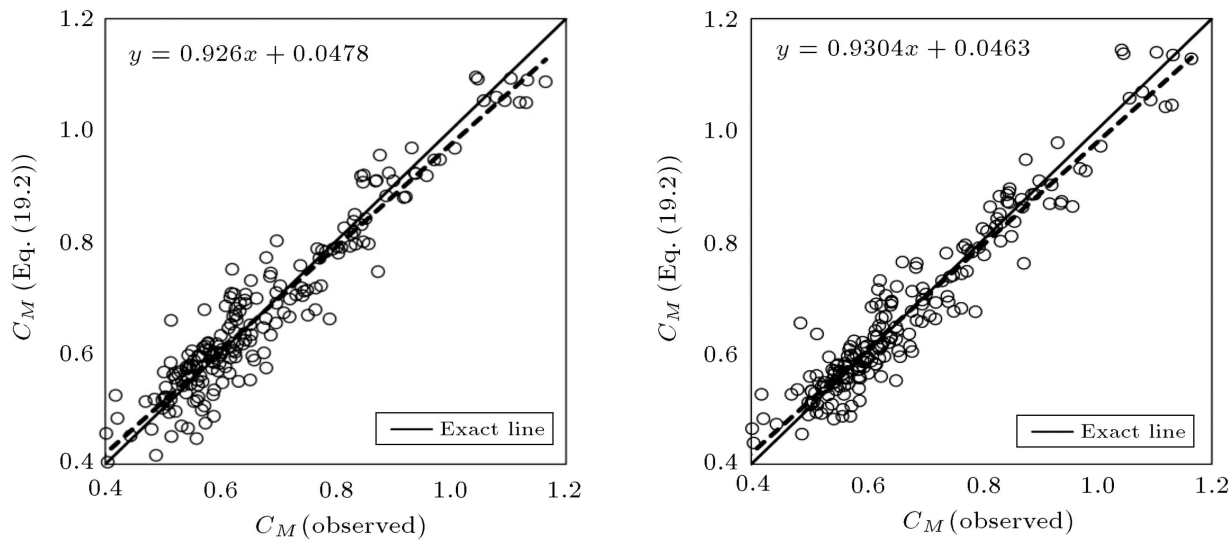

(a)

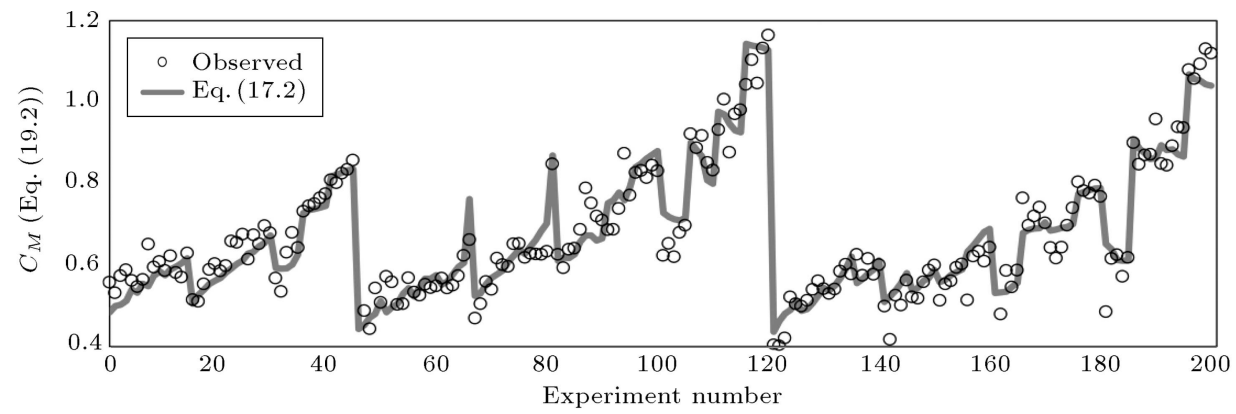

(b)

Figure 4. (a) Scatter plot of comparing the observed $C_{M}$ and the estimated $C_{M}$ by Eqs. (19.1) and (19.2). (b) Comparison of the observed $C_{M}$ and the estimated $C_{M}$ by Eq. (19.2). 
(19.1). In Figure 4(b), the results of laboratory tests are compared with those obtained from Eq. (19.2). It is evident that the accuracy problems in Eq. (8) (Figure 3(b)) in test numbers 20 to 40 and 100 to 120 are almost solved; the results are agreeable.

\subsection{Optimized 2nd-order equation}

The main objective herein is to determine equations of high accuracy featuring simple standard forms. Therefore, the accuracy of the 2 nd-order equations was investigated. Thus, $C_{M}$ equation resembles Eq. (20). In this equation, $a_{1}$ is the equation's constant value, and $a_{2}$ to $a_{9}$ are the coefficients that make the 2ndorder equation. In Eq. (20), $\operatorname{Var}_{1}$ to $\operatorname{Var}_{4}$ are used as inputs from INPUT1 and INPUT2. Table 4 presents $a_{1}$ to $a_{9}$ coefficients as calculated from the PSO algorithm for Eqs. (20.1) and (20.2) with INPUT1 and INPUT2 as input variables, respectively. It is apparent that MSE in Eq. (20.2) using INPUT2 is less than that of Eq. (20.1) using INPUT1, indicating that INPUT2 combination gives more accurate results. Note that the very simple Eq. (20) gives much more accurate results than the complex Eq. (8) does. Higher MSEs in Eqs. (20.1) and (20.2) than those in Eqs. (19.1) and (19.2) may demonstrate that Eq. (19) has an optimized shape and is more efficient for modeling the discharge coefficient of the modified triangular side weir. However, as stated above, the main advantage of Eq. (20) is its simplicity and its standard shape. In Figure 5(a), the estimated values of Eqs. (20.1) and (20.2) for INPUT1 and INPUT2 are plotted on the ordinate; the laboratory values are plotted on the

Table 4. Characteristics and statistical errors of Eqs. (20.1) and (20.2).

\begin{tabular}{|c|c|c|c|c|c|c|c|c|c|}
\hline \multirow{4}{*}{$\begin{array}{c}\text { INPUT1 } \\
\text { Eq. }(20.1)\end{array}$} & $a_{1}$ & $a_{2}$ & $a_{3}$ & $a_{4}$ & $a_{5}$ & $a_{6}$ & $a_{7}$ & $a_{8}$ & $a_{9}$ \\
\hline & 0.25 & -2.58 & 1.16 & 1.42 & -0.47 & 0.31 & 0.03 & 2.14 & -2.44 \\
\hline & MSE & RMSE & MAE & MAPE & & & & & \\
\hline & 0.0032 & 0.057 & 0.044 & 0.033 & & & & & \\
\hline \multirow{4}{*}{$\begin{array}{c}\text { INPUT2 } \\
\text { Eq. }(20.2)\end{array}$} & $a_{1}$ & $a_{2}$ & $a_{3}$ & $a_{4}$ & $a_{5}$ & $a_{6}$ & $a_{7}$ & $a_{8}$ & $a_{9}$ \\
\hline & 1.41 & -1.64 & 1.98 & -0.53 & 0.020 & 2.67 & -0.77 & -4.43 & 2.39 \\
\hline & MSE & RMSE & MAE & MAPE & & & & & \\
\hline & 0.0029 & 0.054 & 0.0413 & 0.031 & & & & & \\
\hline
\end{tabular}
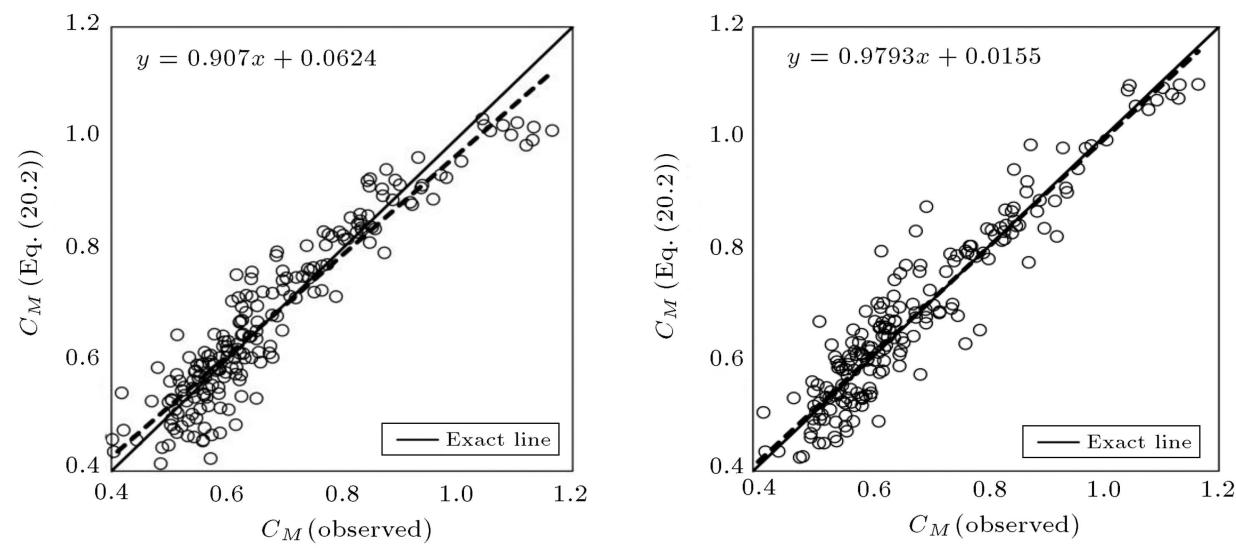

(a)

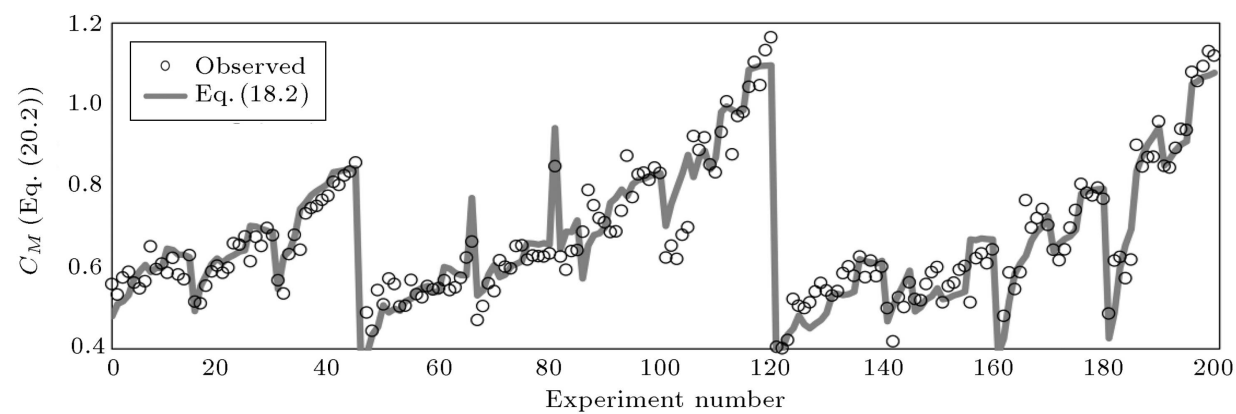

(b)

Figure 5. (a) Scatter plot of comparing the observed $C_{M}$ and the estimated $C_{M}$ by Eqs. (20.1) and (20.2). (b) Comparison of the observed $C_{M}$ and the estimated $C_{M}$ by Eq. (20.2). 
Table 5. Characteristics and statistical errors of Eqs. (21.1) and (21.2).

\begin{tabular}{|c|c|c|c|c|c|c|c|c|c|c|c|c|c|}
\hline \multirow{4}{*}{$\begin{array}{l}\text { INPUT1 } \\
\text { Eq. }(21.1)\end{array}$} & $a_{1}$ & $a_{2}$ & $a_{3}$ & $a_{4}$ & $a_{5}$ & $a_{6}$ & $a_{7}$ & $a_{8}$ & $a_{9}$ & $a_{10}$ & $a_{11}$ & $a_{12}$ & $a_{13}$ \\
\hline & 0.42 & 3.11 & -0.13 & -1.20 & - & 2.37 & - & 5.91 & - & 0.46 & - & 2.95 & - \\
\hline & MSE & RMSE & MAE & MAPE & & & & & & & & & \\
\hline & 0.0031 & 0.056 & 0.0439 & 0.033 & & & & & & & & & \\
\hline \multirow{4}{*}{$\begin{array}{c}\text { INPUT2 } \\
\text { Eq. }(21.2)\end{array}$} & $a_{1}$ & $a_{2}$ & $a_{3}$ & $a_{4}$ & $a_{5}$ & $a_{6}$ & $a_{7}$ & $a_{8}$ & $a_{9}$ & $a_{10}$ & $a_{11}$ & $a_{12}$ & $a_{13}$ \\
\hline & -0.20 & 0.37 & -3.18 & 4.45 & - & 0.82 & - & 3.19 & 0 & - & 0.36 & - & 2.07 \\
\hline & MSE & RMSE & MAE & MAPE & & & & & & & & & \\
\hline & 0.0029 & 0.054 & 0.0405 & 0.030 & & & & & & & & & \\
\hline
\end{tabular}

abscissa. Note the excessive closeness of the fit and exact lines of this equation to the extent that they overlap in Eq. (20.2). The closeness between these two lines means that errors in the data are scattered equally around the exact line. It could be inferred that this symmetry is due to the greater symmetry of Eq. (20) as compared to Eq. (19). Notice that this symmetry bears no relation to the accuracy of the model; for example, in Eq. (19.2), MSE (0.0021) is less than MSE of Eq. (20.2) (0.0029); however, in Eq. (20.2), $c_{1}$ and $c_{2}$ coefficients are closer to 1 and 0 , respectively, making the error results completely symmetrical. In Figure 5(b), the suggested results derived from Eq. (20.2) are presented with bold fonts on the ordinate, and the laboratory test results are plotted with empty circles. The number of tests is plotted on the abscissa. The comparison made between Figures 5(b) and 4(b) shows that the results in areas where $C_{M}$ does not experience dramatic fluctuations (e.g., experiment numbers 0 to 30 ) are more accurate than those of Eq. (19.2) are. The disadvantage of using this equation in $C_{M}$ modeling is clear in areas where the discharge coefficient undergoes a variation (experiment numbers 100 to 120 ). The results indicate that this simple equation is valid and can have practical uses due to the non-dimensionality of the data:

$$
\begin{aligned}
C_{M}= & a_{1}+\left[a_{2}\left(\operatorname{Var}_{1}\right)+a_{3}\left(\operatorname{Var}_{1}\right)^{2}\right] \\
& +\left[a_{4}\left(\operatorname{Var}_{2}\right)+a_{5}\left(\operatorname{Var}_{2}\right)^{2}\right] \\
& +\left[a_{6}\left(\operatorname{Var}_{3}\right)+a_{7}\left(\operatorname{Var}_{3}\right)^{2}\right] \\
& +\left[a_{8}\left(\operatorname{Var}_{4}\right)+a_{9}\left(\operatorname{Var}_{4}\right)^{2}\right]
\end{aligned}
$$

\subsection{Optimized 3rd-order equation}

After studying the equation with the 2nd-order structure and having favorite equations to calculate discharge coefficient $C_{M}$ of the modified triangular side weir (Eqs. (20.1) and (20.2)), the standard structure of the polynomial of a 3rd-order equation was investigated along with the general structure, as shown in Eq. (21). Herein, $a_{1}$ is a constant, and $a_{2}$ to $a_{13}$ are the equation's coefficients. The PSO algorithm was used to solve a 13dimensional problem and calculate the proper values for $a_{1}$ to $a_{13}$. Table 5 shows the calculated values of INPUT1 (Eq. (21.1)) and INPUT2 (Eq. (21.2)) in Eq. (21). From this table, as introduced in other equations, the equation's error in which INPUT2 is used is less than that when INPUT1 is used. Figure 6(a) shows $C_{M}$ results obtained from Eqs. (21.1) and (21.2) and compares them with the laboratory values. The comparison between Eq. (20.2) and Eqs. (21.1) and (21.2) indicates that if the power of the multi-term equation is changed from 2 to 3 , the accuracy of the model does not increase noticeably. As Figure 6(a) shows, the fit and exact lines have less adaptation than Figure 5(a) do. A comparison of Figure 5(b) with Figure 6(b) shows that Eq. (20.2) provides more accurate results in both areas, i.e. where the changes in $C_{M}$ are uniform and where there are sudden changes in $C_{M}$. Since the objective of this study is to determine an applicable equation to calculate $C_{M}$ of a modified triangular side weir and considering simplicity and shortness as the major criteria of applicability, it can be inferred that increasing the polynomial's power from 2 to 3 does not provide a more efficient equation for calculating $C_{M}$ :

$$
\begin{aligned}
C_{M}= & a_{1}+\left[a_{2}\left(\operatorname{Var}_{1}\right)+a_{3}\left(\operatorname{Var}_{1}\right)^{2}+a_{4}\left(\operatorname{Var}_{1}\right)^{3}\right] \\
& +\left[a_{5}\left(\operatorname{Var}_{2}\right)+a_{6}\left(\operatorname{Var}_{2}\right)^{2}+a_{7}\left(\operatorname{Var}_{2}\right)^{3}\right] \\
& +\left[a_{8}\left(\operatorname{Var}_{3}\right)+a_{9}\left(\operatorname{Var}_{3}\right)^{2}+a_{10}\left(\operatorname{Var}_{3}\right)^{3}\right] \\
& +\left[a_{11}\left(\operatorname{Var}_{4}\right)+a_{12}\left(\operatorname{Var}_{4}\right)^{2}+a_{13}\left(\operatorname{Var}_{4}\right)^{3}\right]
\end{aligned}
$$

\subsection{Optimized nonlinear equation}

A comparison of MSEs resulting from Eqs. (19.2) and (20.2), i.e. 0.0021 and 0.0029 , respectively, shows that the lower error in Eq. (19.2) is more likely due to the constant values considered as powers of the input variables. If we intend to reduce MSE, the idea of using a standard, nonlinear equation, such as Eq. (22), may play an instrumental role. In Eq. (22), for each input variable, one coefficient $\left(a_{8}, a_{6}, a_{4}, a_{2}\right)$ and one 

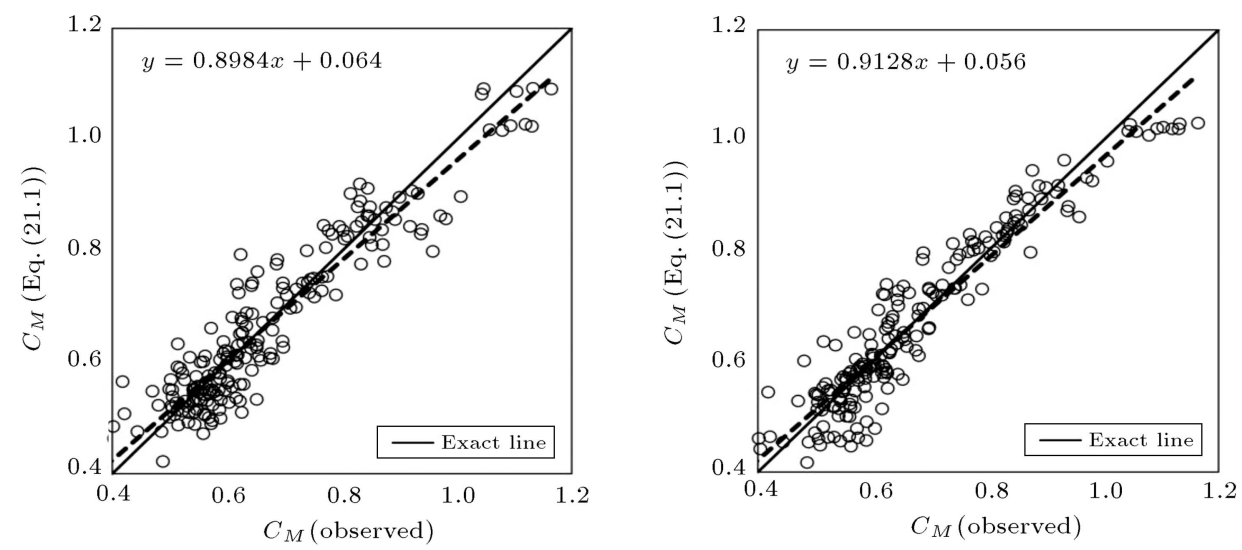

(a)

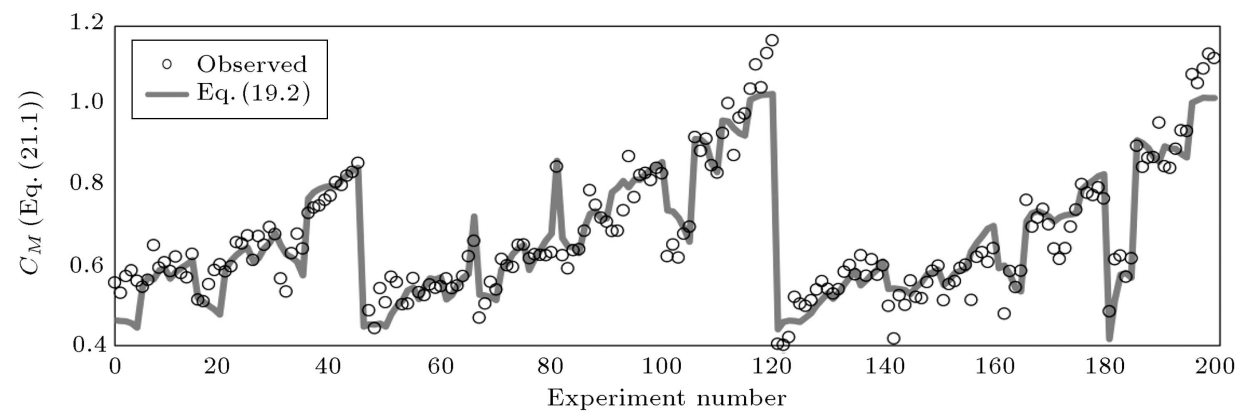

(b)

Figure 6. (a) Scatter plot of comparing the observed $C_{M}$ and the estimated $C_{M}$ by Eqs. (21.1) and (21.2). (b) Comparison of the observed $C_{M}$ and the estimated $C_{M}$ by Eq. (21.2).

Table 6. Characteristics and statistical errors of Eqs. (22.1) and (22.2).

\begin{tabular}{|c|c|c|c|c|c|c|c|c|c|}
\hline \multirow{4}{*}{$\begin{array}{l}\text { INPUT1 } \\
\text { Eq. }(22.1)\end{array}$} & $a_{1}$ & $a_{2}$ & $a_{3}$ & $a_{4}$ & $a_{5}$ & $a_{6}$ & $a_{7}$ & $a_{8}$ & $a_{9}$ \\
\hline & 0.93 & -0.08 & 0.95 & -0.20 & 1.19 & 1.06 & 1.44 & -1.48 & 1.11 \\
\hline & MSE & RMSE & MAE & MAPE & & & & & \\
\hline & 0.0022 & 0.047 & 0.0373 & 0.028 & & & & & \\
\hline \multirow{4}{*}{$\begin{array}{c}\text { INPUT2 } \\
\text { Eq. }(22.2)\end{array}$} & $a_{1}$ & $a_{2}$ & $a_{3}$ & $a_{4}$ & $a_{5}$ & $a_{6}$ & $a_{7}$ & $a_{8}$ & $a_{9}$ \\
\hline & 0.28 & -0.22 & 9.99 & -0.27 & 1.12 & 1.84 & 0.61 & -1.66 & 0.91 \\
\hline & MSE & RMSE & MAE & MAPE & & & & & \\
\hline & 0.0020 & 0.045 & 0.035 & 0.026 & & & & & \\
\hline
\end{tabular}

power $\left(a_{9}, a_{7}, a_{5}, a_{3}\right)$ were considered. As was the case with previous equations, one constant value $\left(a_{1}\right)$ was considered for all of the equations. Then, $a_{1}$ to $a_{9}$ were calculated with the PSO algorithm, and the optimization results and MSE values for INPUT1 and INPUT2 are given in Table 6 as Eqs. (22.1) and (22.2). As with other previous equations, the error value was lower in INPUT2. The interesting point here is that the error value was at its minimum compared with other equations. Since the shape of Eq. (22) is simple and standard, it can model the discharge coefficient $\left(C_{M}\right)$ of a modified triangular side weir coefficient with an insignificant error. Figure 7(a) shows that this equation reduces the error to a minimum; however, the fit and exact lines do not overlap as they do in Eq. (20.2). A comparison of Figure 5(b) with Figure 7(b) shows that Eq. (20.2) has more efficient performance than Eq. (22.2) for experiment numbers 0 to 40, while Eq. (22.2) has higher accuracy with respect to the other experiment numbers. A comparison of Figure 4(b) with Figure $7(\mathrm{~b})$ shows that both models are too weak to model experiment numbers 0 to 40; however, Eq. (19.2) functions better in areas where $C_{M}$ experiences sudden changes (experiment numbers 100 to 120 ):

$$
\begin{aligned}
C_{M}= & a_{1}+a_{2}\left(\operatorname{Var}_{1}\right)^{a_{3}}+a_{4}\left(\operatorname{Var}_{2}\right)^{a_{5}}+a_{6}\left(\operatorname{Var}_{3}\right)^{a_{7}} \\
& +a_{8}\left(\operatorname{Var}_{4}\right)^{a_{9}} .
\end{aligned}
$$


Table 7. AIC amounts for the considered models.

\begin{tabular}{cccccccccc}
\hline & \multicolumn{8}{c}{ Eq. Nos. } \\
\cline { 2 - 9 } & $\mathbf{( 8 )}$ & $\mathbf{( 1 9 . 1 )}$ & $\mathbf{( 1 9 . 2 )}$ & $\mathbf{( 2 0 . 1 )}$ & $\mathbf{( 2 0 . 2 )}$ & $\mathbf{( 2 1 . 1 )}$ & $\mathbf{( 2 1 . 2 )}$ & $\mathbf{( 2 2 . 1 )}$ & $\mathbf{( 2 2 . 2 )}$ \\
\hline SSE & 0.732 & 0.472 & 0.426 & 0.642 & 0.575 & 0.624 & 0.573 & 0.443 & 0.425 \\
$\boldsymbol{k}$ & 9 & 9 & 9 & 10 & 10 & 14 & 14 & 10 & 10 \\
$\mathbf{A I C}$ & -1104 & -1192 & -1212 & -1128 & -1150 & -1126 & -1143 & -1202 & -1211 \\
\hline
\end{tabular}
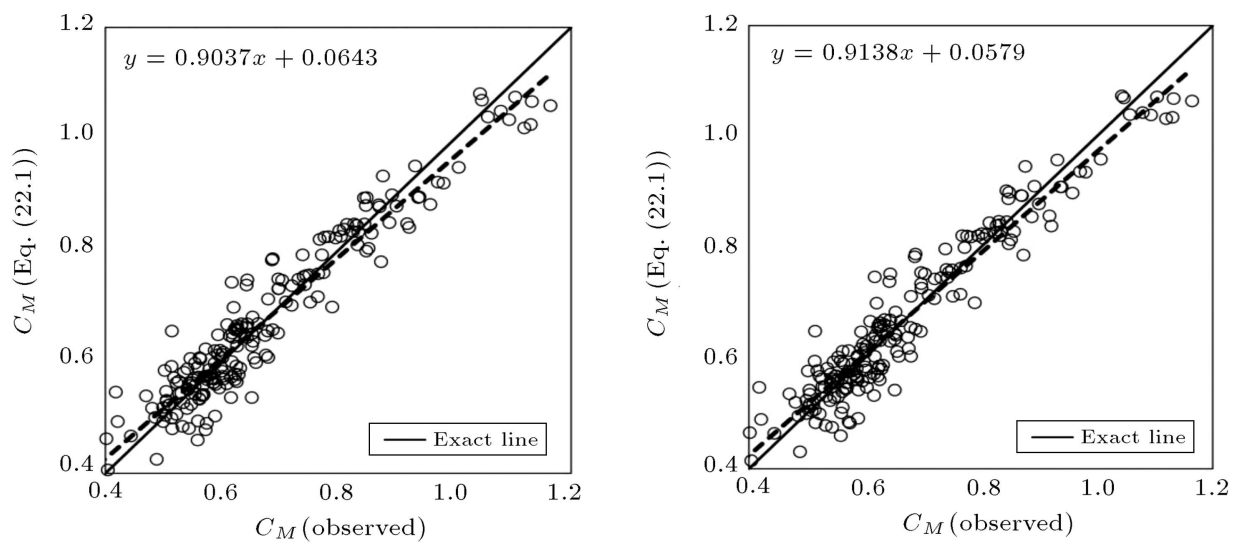

(a)

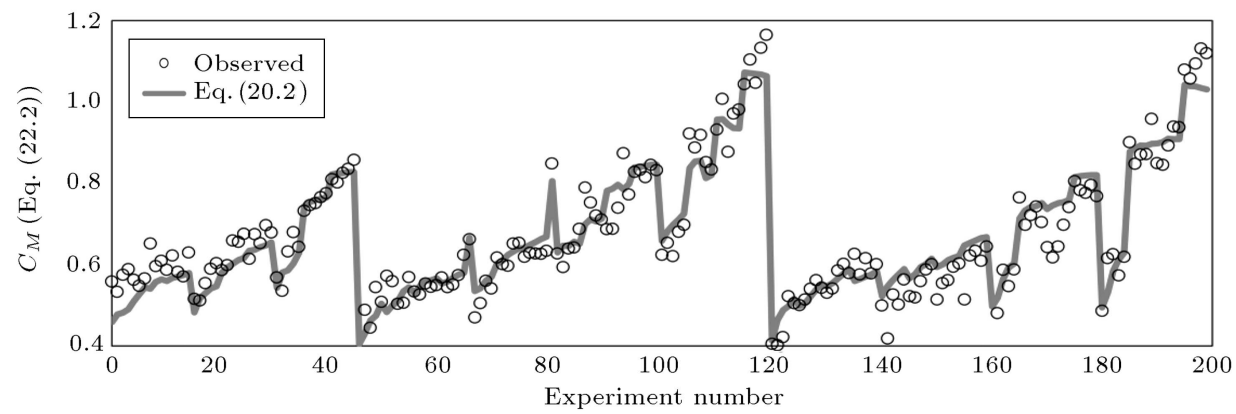

(b)

Figure 7. (a) Scatter plot of comparing observed $C_{M}$ and the estimated $C_{M}$ by Eqs. (22.1) and (22.2). (b) Comparison of the observed $C_{M}$ and the estimated $C_{M}$ by Eq. (22.2).

\subsection{Akaike Information Criterion (AIC)}

By adding parameters to the model constantly, it may work somewhat better; however, overfitting and information loss concerning the real pattern may occur. Therefore, AIC [50-52] represents a trade-off between the number of parameters involved in the model and the increase or decrease of error. AIC is used to select a model by considering not only the error, but also the number of parameters used to develop the model. By assuming that the errors are normally distributed in the model, AIC equation is obtained as follow:

$$
\mathrm{AIC}=n \log \left(\frac{S S E}{n}\right)+2 k
$$

where $n$ is the number of observations, $k$ is the number of used parameters used in the model plus one, and SSE is the Sum of Squared Errors of the model.
The parameters used in this equation for the models developed in the present study are shown in Table 7 .

According to AIC formulation, the model enjoying a better fit has lower AIC value. Based on Tables 3 and 6, Eq. (22.2) with RMSE of 0.045 performed somewhat better than the Eq. (19.2) with RMSE of 0.049 did. However, Table 7 shows that the number of involved parameters of Eq. (22.2) is more than that of Eq. (19.2)'s parameters. Therefore, Eq. (19.2) with AIC of -1212 has the best-fit score according to this criterion.

\section{Conclusions}

In this research, a PSO model was developed to determine the discharge coefficients of modified triangular side weirs. Two hundred experimental datasets were used for the PSO model. Four different equation forms 
were used to determine the most accurate form; in each form, two non-dimensional parameters were used as inputs to the PSO model. As shown, the second input series provided more accurate results and included $w / L$ (weir height/weir length), $\mathrm{Fr}_{1} / \operatorname{sine}\left(\theta^{\prime}\right)$ (upstream Froude number/sine (weir included angle/2)), $w / Y_{1}$ (weir height/upstream flow depth), and $w \times \operatorname{sine}\left(\theta^{\prime}\right) / Y_{1}$ ((weir included angle/2)/upstream flow depth). The equations based on the PSO algorithm were compared with a nonlinear regression model, and it was found that they were more accurate than the regression models. After comparing four forms of the equations used in this study, it was determined that the performance of the power equation is better than those of the other forms are. It also was determined that a combination of the PSO algorithm with a power equation could be used successfully to compute the discharge coefficients of modified triangular side weirs.

\section{References}

1. De Marchi, G. "Lateral weirs fundamentals" [Saggio di teoria del funzionamento degli stramazzi laterali, L'Energia Elettrica. (In Italian), 11(11), pp. 849-860 (1934).

2. Ackers, P. "A theoretical consideration of side-weirs as storm water overflows", Pros. ICE, 6, pp. 250-269 (1957).

3. Yu-Tech, L. "Discussion of spatially varied flow over side weir", Journal of Hydrologic Engineering, 98(11), pp. 2046-2048 (1972).

4. Singh, R., Manivannan, D., and Satyanarayana, T. "Discharge coefficient of rectangular side weirs", Journal of Irrigation and Drainage Engineering, 120(4), pp. 814-819 (1994).

5. Swamee, P.K., Pathak, S.K., and Ali, M.S. "Side-weir analysis using elementary discharge coefficient", Journal of Irrigation and Drainage Engineering, 120(4), pp. 742-755 (1994).

6. Ura, M., Kita, Y., Akiyama, J., Moriyama, H., and Kumar, J.A. "Discharge coefficient of oblique sideweirs", Journal of Hydroscience and Hydraulic Engineering, 19(1), pp. 85-96 (2001).

7. Borghei, S.M. and Parvaneh, A. "Discharge characteristics of a modified oblique side weir in subcritical flow", Flow Measurement and Instrumentation, 22(5), pp. 370-376 (2011).

8. Najafzadeh, M. and Barani, G.A. "Comparison of group method of data handling based genetic programming and back propagation systems to predict scour depth around bridge piers", Scientia Iranica, 18(6), pp. 1207-1213 (2011).

9. Najafzadeh, M. and Azamathulla, H.M. "Group method of data handling to predict scour depth around bridge piers", Neural Computing and Applications, 23(7), pp. 2107-2112 (2013).
10. Najafzadeh, M., Barani, G.-A., and Hessami Kermani, M.R. "GMDH based back propagation algorithm to predict abutment scour in cohesive soils", Ocean Engineering, 59, pp. 100-106 (2013).

11. Najafzadeh, M., Barani, G.-A., and Hessami-Kermani, M.-R. "Group method of data handling to predict scour at downstream of a ski-jump bucket spillway", Earth Science Informatics, 7(4), pp. 231-248 (2014).

12. Najafzadeh, M. and Lim, S.Y. "Application of improved neuro-fuzzy GMDH to predict scour depth at sluice gates", Earth Science Informatics, 8(1), pp. 187196 (2015).

13. Najafzadeh, M. "Neuro-fuzzy GMDH based particle swarm optimization for prediction of scour depth at downstream of grade control structures", Engineering Science and Technology, an International Journal, 18(1), pp. 42-51 (2015).

14. Grace, J.L. and Priest, M.S., Division of Flow in Open Channel Junctions, Engineering Experiment Station, Alabama Polytechnic Institute (1958).

15. Moré, J. "The Levenberg-Marquardt algorithm: Implementation and theory", Watson, G.A. (Ed.) In Numerical Analysis, pp. 105-116, Springer Berlin Heidelberg (1978).

16. Chau, K., Wu, C., and Li, Y. "Comparison of several flood forecasting models in Yangtze River", Journal of Hydrologic Engineering, 10(6), pp. 485-491 (2005).

17. Cheng, C., Chau, K., Sun, Y., and Lin, J. "Long-Term Prediction of Discharges in Manwan Reservoir Using Artificial Neural Network Models", Wang, J., Liao, X.F., and Yi, Z. (Eds.), In Advances in Neural Networks ISNN 2005, pp. 1040-1045, Springer Berlin Heidelberg (2005).

18. Chen, W. and Chau, K. "Intelligent manipulation and calibration of parameters for hydrological models", International Journal of Environment and Pollution, 28(3), pp. 432-447 (2006).

19. Firat, M. and Gungor, M. "Hydrological time-series modelling using an adaptive neuro-fuzzy inference system", Hydrological Processes, 22(13), pp. 2122-2132 (2008).

20. Wu, C., Chau, K., and Li, Y. "Predicting monthly streamflow using data-driven models coupled with data-preprocessing techniques", Water Resources Research, 45(8), p. W08432 (2009).

21. Asadi, S., Shahrabi, J., Abbaszadeh, P., and Tabanmehr, S. "A new hybrid artificial neural networks for rainfall-runoff process modeling", Neurocomputing, 121, pp. 470-480 (2013).

22. Yurtseven, I. and Zengin, M. "Neural network modelling of rainfall interception in four different forest stands", Annals of Forest Research, 56(2), pp. 351-362 (2013).

23. Muttil, N. and Chau, K.-W. "Neural network and genetic programming for modelling coastal algal blooms", International Journal of Environment and Pollution, 28(3), pp. 223-238 (2006). 
24. Kisi, O. and Ozturk, O. "Adaptive neurofuzzy computing technique for evapotranspiration estimation", Journal of Irrigation and Drainage Engineering, 133(4), pp. 368-379 (2007).

25. Cobaner, M. "Evapotranspiration estimation by two different neuro-fuzzy inference systems", Journal of Hydrology, 398(3), pp. 292-302 (2011).

26. Hager, W.H. "Discussion of separation zone at openchannel junctions", Journal of Hydraulic Engineering, 113(4), pp. 539-543 (1987).

27. Najafzadeh, M. and Tafarojnoruz, A. "Evaluation of neuro-fuzzy GMDH-based particle swarm optimization to predict longitudinal dispersion coefficient in rivers", Environmental Earth Sciences, 75(2), p. 157 (2016).

28. Maanen, B.V., Coco, G., Bryan, K.R., and Ruessink, B. "The use of artificial neural networks to analyze and predict alongshore sediment transport", Nonlinear Processes in Geophysics, 17(5), pp. 395-404 (2010).

29. Ebtehaj, I. and Bonakdari, H. "Evaluation of sediment transport in sewer using artificial neural network", Engineering Applications of Computational Fluid Mechanics, 7 (3), pp. 382-392 (2013).

30. Taormina, R., Chau, K.-W., and Sethi, R. "Artificial neural network simulation of hourly groundwater levels in a coastal aquifer system of the Venice lagoon", Engineering Applications of Artificial Intelligence, 25(8), pp. 1670-1676 (2012).

31. Pulido-Calvo, I. and Gutiérrez-Estrada, J.C. "Improved irrigation water demand forecasting using a soft-computing hybrid model", Biosystems Engineering, 102(2), pp. 202-218 (2009).

32. Tiwari, M.K. and Adamowski, J. "Urban water demand forecasting and uncertainty assessment using ensemble wavelet-bootstrap-neural network models", Water Resources Research, 49(10), pp. 6486-6507 (2013).

33. Najafzadeh, M. and Sattar, A.M.A. "Neuro-fuzzy GMDH approach to predict longitudinal dispersion in water networks", Water resources management, 29(7), pp. 2205-2219 (2015).

34. Bilhan, O., Emin Emiroglu, M., and Kisi, O. "Application of two different neural network techniques to lateral outflow over rectangular side weirs located on a straight channel", Advances in Engineering Software, 41(6), pp. 831-837 (2010).

35. Kisi, O., Emin Emiroglu, M., Bilhan, O., and Guven, A. "Prediction of lateral outflow over triangular labyrinth side weirs under subcritical conditions using soft computing approaches", Expert Systems with Applications, 39(3), pp. 3454-3460 (2012).

36. Emin Emiroglu, M., Kisi, O., and Bilhan, O. "Predicting discharge capacity of triangular labyrinth side weir located on a straight channel by using an adaptive neuro-fuzzy technique", Advances in Engineering Software, 41(2), pp. 154-160 (2010).
37. Bilhan, O., Emiroglu, M.E., and Kisi, O. "Use of artificial neural networks for prediction of discharge coefficient of triangular labyrinth side weir in curved channels", Advances in Engineering Software, 42(4), pp. 208-214 (2011).

38. Emiroglu, M.E., Bilhan, O., and Kisi, O. "Neural networks for estimation of discharge capacity of triangular labyrinth side-weir located on a straight channel", Expert Systems with Applications, 38(1), pp. 867-874 (2011).

39. Neary, V. and Sotiropoulos, F. "Numerical investigation of laminar flows through 90-degree diversions of rectangular cross-section", Computers \& Fluids, 25(2), pp. 95-118 (1996).

40. Khorchani, M. and Blanpain, O. "Development of a discharge equation for side weirs using artificial neural networks", Journal of Hydroinformatics, 7, pp. 31-39 (2005).

41. Dursun, O.F., Kaya, N., and Firat, M. "Estimating discharge coefficient of semi-elliptical side weir using ANFIS", Journal of Hydrology, 426, pp. 55-62 (2012).

42. Bagheri, S., Kabiri-Samani, A., and Heidarpour, M. "Discharge coefficient of rectangular sharp-crested side weirs, Part I: Traditional weir equation", Flow Measurement and Instrumentation, 35, pp. 109-115 (2013).

43. Kennedy, J. and Eberhart, R. "Particle swarm optimization", Proceedings of IEEE international conference on neural networks, Perth, Australia, pp. 19421948 (1995).

44. Tripathi, P.K., Bandyopadhyay, S., and Pal, S.K. "Multi-objective particle swarm optimization with time variant inertia and acceleration coefficients", Information Sciences, 177(22), pp. 5033-5049 (2007).

45. Chatterjee, A. and Siarry, P. "Nonlinear inertia weight variation for dynamic adaptation in particle swarm optimization", Computers \& Operations Research, 33(3), pp. 859-871 (2006).

46. Helton, J., Iman, R., Johnson, J., and Leigh, C. "Uncertainty and sensitivity analysis of a model for multicomponent aerosol dynamics", Nuclear Technology, 73(3), pp. 320-342 (1986).

47. Iman, R.L. and Helton, J.C. "An investigation of uncertainty and sensitivity analysis techniques for computer models", Risk Analysis, 8(1), pp. 71-90 (1988).

48. Downing, D.J., Gardner, R., and Hoffman, F. "An examination of response-surface methodologies for uncertainty analysis in assessment models", Technometrics, 27(2), pp. 151-163 (1985).

49. Hamby, D.M. "A review of techniques for parameter sensitivity analysis of environmental models", Environmental Monitoring and Assessment, 32(2), pp. 135154 (1994).

50. Akaike, H. "Information theory and an extension of the maximum likelihood principle", Kotz, S. and Johnson, N.L. (Eds.), In Breakthroughs in Statistics: Foundations and Basic Theory, pp. 610-624, Springer New York, New York, NY (1992). 
51. Akaike, H. "A new look at the statistical model identification", IEEE Transactions on Automatic Control, 19(6), pp. 716-723 (1974).

52. Akaike, H. "Prediction and entropy", Atkinson, A.C. and Fienberg, S.E. (Eds.), In A Celebration of Statistics: The ISI Centenary Volume A Volume to Celebrate the Founding of the International Statistical Institute in 1885, pp. 1-24, Springer New York, New York, NY (1985).

\section{Biographies}

Amir Hossein Zaji is now a PhD Student in Hydraulic Structures (Civil Engineering), Department of Civil Engineering, University of Razi, Kermanshah, Iran. He has 20 published papers in ISI journals. He works in the field of soft computing methods in engineering applications. He has been rated as a distinguished researcher in Razi University, 2015.

Hossein Bonakdari is a Professor at the Department of Civil Engineering of University of Razi University; he earned his $\mathrm{PhD}$ in Civil Engineering at the University of Caen-France. After obtaining PhD, Dr. Bonakdari joined University of Razi as a faculty member in 2006; presently, he is a Professor at the Department of Civil Engineering. He has supervised 5 $\mathrm{PhD}$ and $30 \mathrm{MS}$ theses. He enjoys brilliant teaching experience of more than 16 years in the field of Civil Engineering. Furthermore, From 2013 till 2015, he was the Director General of Training, Research and
Technology Development at Ministry of Energy, Iran and also the Deputy of Planning \& Development in National Water and Wastewater Engineering Company, Iran, from 2011-2013. His fields of specialization and interest include practical application of soft computing in engineering, modeling of wastewater urban drainage systems, sediment transport, computational fluid dynamic and hydraulics, design of hydraulic structures and fluid mechanics. From 2010 till 2011, he has been a researcher at Laboratory of Civil and Environmental Engineering, INSA of Lyon, France. Results obtained from his researches have been published in more than 100 papers in international journals (h-index=13). He has also more than 150 presentations in national and international conferences. He published two books. He has been rated as a distinguished researcher in Razi University, 2014, 2015 and 2016.

Shahaboddin Shamshirband is now a Senior Lecturer at the Department of Computer System and Technology, University of Malaya. He received his MSc degree in Computer Science from Islamic Azad University of Mashhad (IAUM), Iran in 2006. He joined the Faculty of Computer Science, Islamic Azad University, Iran for seven years. Currently, he is pursuing his $\mathrm{PhD}$ from the University of Malaya, Malaysia. He is working in a multi-disciplinary environment involving applications of computational intelligence and neurocomputing in Civil Engineering. He has published more than one hundred papers in ISI journals. 